\title{
Studying Maxillary Labial Frenulum Types and Their Effect on Median Diastema in 3-6-year-old Children in Tehran Kindergartens
}

\author{
Bahman Seraj ${ }^{1}$, Mahdi Shahrabi ${ }^{2}$, Samaneh Masoumi ${ }^{3}$, Razieh Jabbarian ${ }^{4}$, Amir A Manesh $^{5}$, Maryam B Fini ${ }^{6}$
}

\begin{abstract}
Background: Diastema is one of the many esthetic abnormalities due to various causes. One of which is abnormal frenulum. Objective: The aim of this study is to determine the prevalence of different types of labial frenum and their effect on median diastema in 3-6-year-old children in Tehran kindergartens.

Materials and methods: This study was a cross-sectional one that was performed on 639 children aged 3-6 years by referring to kindergartens. Studying these children included oral examination under normal light with a tongue depressor in upright position. By lifting the patient's lip and performing a blanching test, it was determined whether or not a person has normal frenulum. Information was also provided about the presence or absence of median diastema in upper jaw and the type of frenum adhesion. Also, the central teeth in maxilla were carefully examined in terms of spacing and caries. Data were analyzed by descriptive and analytic statistical methods. In the analytic part we used the binomial logistic regression test and also in the descriptive section of the frequency, tables and graphs are presented.
\end{abstract}

Conclusion: In this research, a total of 639 children were studied, 341 of which were male and 298 were female. Among these 214 people (33.5\%) had abnormal frenum and 425 people $(66.5 \%)$ had normal frenum. Frenum adhesion site for $52.9 \%$ of the people was observed in attached gingiva and for $19.9 \%$ of people was observed in the mucogingival junction and for $18.8 \%$ of people was observed in the interdental papilla and for $8.5 \%$ of people the site of frenulum was in depth of the palatal papilla, and there was no significant difference between two sexes in terms of prevalence of different types of maxilla labial frenum. The results showed that there is a significant relationship between high frenum and maxillary median diastema and there is no significant relationship between age and high frenum.

Keywords: Diastema, Maxillary labial frenum, Preschool children.

World Journal of Dentistry, (2019): 10.5005/jp-journals-10015-1611

\section{INTRODUCTION}

$\mathrm{O}$ ne of the disorders that affect the beauty and causes discomfort to the patients and parents, is the diastema between the upper central incisors. This space is called the midline diastema' (Fig. 1).

The diastema between the upper central incisor teeth creates an ugly view that affects patient discomfort. This space has little effect on mastication, and its treatment is done for esthetic reasons. ${ }^{1}$

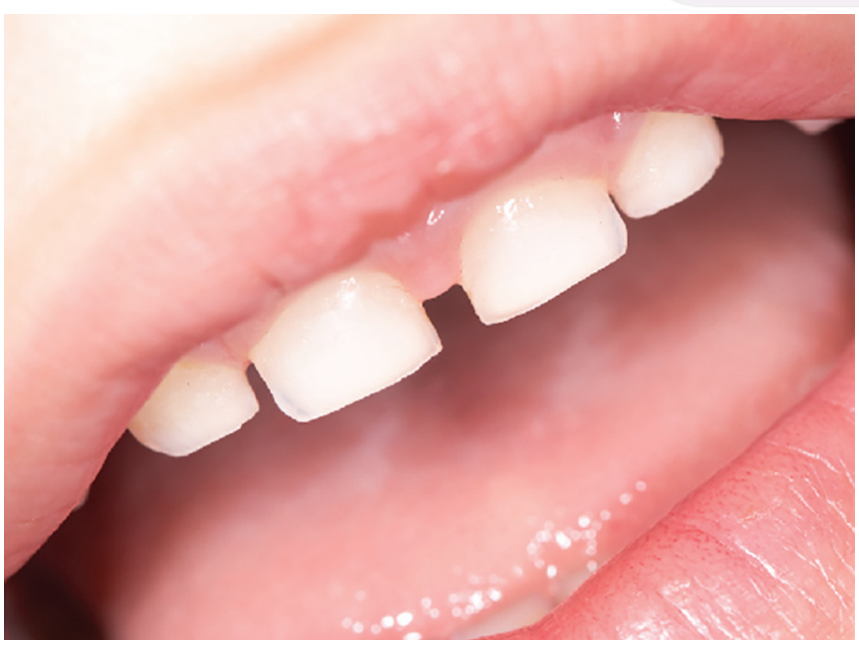

Fig. 1: Midline diastema
1,2Department of Pediatrics, School of Dentistry, Tehran University of Medical Sciences, Tehran, Islamic Republic of Iran

${ }^{3}$ Department of Periodontics, School of Dentistry, Qom University of Medical Sciences, Qom, Islamic Republic of Iran

${ }^{4}$ Department of Periodontics, School of Dentistry, Qazvin University of Medical Sciences, Qazvin, Islamic Republic of Iran

${ }^{5}$ Department of Periodontology, Faculty of Medicine, Comenius University, Bratislava, Slovak Republic

${ }^{6}$ Tehran University of Medical Sciences, Tehran, Islamic Republic of Iran

Corresponding Author: Maryam B Fini, Tehran University of Medical Sciences, Tehran, Islamic Republic of Iran, Phone: +1 (405) 334-1239, e-mail:m.baghizadeh92@gmail.com

How to cite this article: Seraj B, Shahrabi M, Masoumi S, Jabbarian R, Manesh AA, Fini MB. Studying Maxillary Labial Frenulum Types and Their Effect on Median Diastema in 3-6-years-old Children in Tehran Kindergartens. World J Dent 2019;10(2):93-97.

Source of support: Nil

Conflict of interest: None

This space between incisors in children is common and physiologic. ${ }^{2}$ Many articles suggest that people with median diastema in the maxillary jaw are less likely to have social success and less self-esteem than others. ${ }^{3}$ Median diastema usually caused by factors such as latrogenic, pathological and developmental problems. ${ }^{4}$ The median diastema is one of the growth characteristics during the mixed dentition, which this space is closed in most children when lateral and canine teeth erupt. ${ }^{5-10}$

(0) The Author(s). 2019 Open Access This article is distributed under the terms of the Creative Commons Attribution 4.0 International License (https://creativecommons. org/licenses/by-nc/4.0/), which permits unrestricted use, distribution, and non-commercial reproduction in any medium, provided you give appropriate credit to the original author(s) and the source, provide a link to the Creative Commons license, and indicate if changes were made. The Creative Commons Public Domain Dedication waiver (http://creativecommons.org/publicdomain/zero/1.0/) applies to the data made available in this article, unless otherwise stated. 
There are different viewpoints on the median diastema between researchers. Angle argued that the median diastema is a common finding in the period of incomplete occlusion. This diastema is seen as the space between the central teeth that occurs in maxilla central teeth more than mandible central teeth. Angle also examined the functional and esthetical problems in the presence of median diastema. ${ }^{11}$

Andrews expressed in an article called the six keys for normal occlusion, the interdental diastema should not be present and all contacts must be completely closed. ${ }^{12}$

Broadbent said that the maxillary median diastema in children growth time is proposed as a nonesthetical factor, and is called "ugly-duckling". He also suggested this stage as one of the transient developmental stages, which disappears with the eruption of lateral and canine teeth, and should not be considered as malocclusion. ${ }^{13}$

As discussed in many articles, a large number of etiologic factors contribute to the development of median diastema. There is no agreement on a single factor, and it seems that a number of factors play a role in it, and median diastema is a multifactorial problem. One of these factors is the frenum abnormalities. ${ }^{14}$ In this study, we attempt to evaluate the prevalence of different types of labia frenum and their effect on median diastema in children aged 3-6 years in Tehran kindergartens.

\section{Materials AND methods}

This is a cross-sectional study. Referring to kindergartens introduced by Tehran province welfare organization, after convincing the nursing authorities and explaining the research design and the usefulness of results for oral health, children aged 3-6 years were examined. The inverse sampling method was used
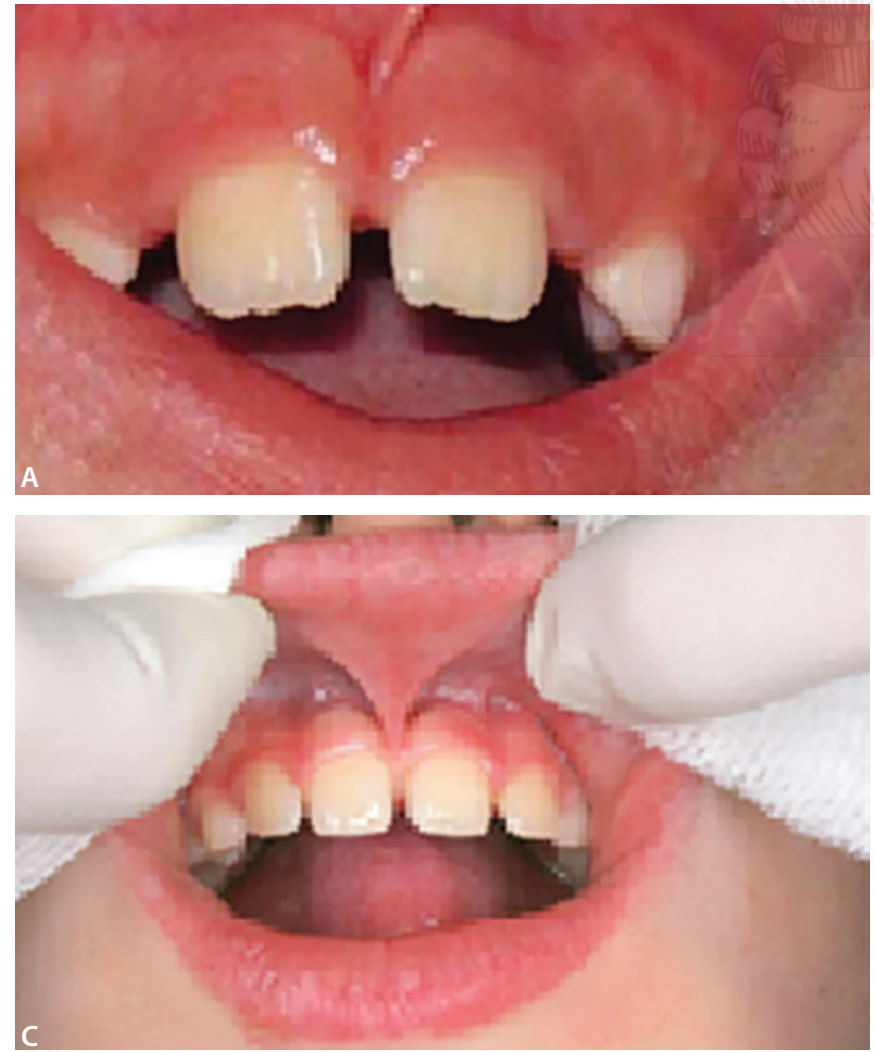

in this study, so that sampling continued to reach 48 abnormal (high) frenum.

Examination of the samples included an oral examination of them under sufficient light and in the upright position by a tongue depressor. The following information was recorded in each patient's sheet: first and last name; age, sex, adhesion type of maxilla labial frenum including mucosal (frenum adhesion in mucogingival junction); gingival (frenum adhesion in attached gingiva); papillary (frenum adhesion in interdental papilla); papilla penetrating (penetration of frenum into palatal papillary) (Fig. 2); the presence or absence of maxillary median diastema, and in the case of presence, measuring it by millimeter ruler; presence of spacing in anterior maxilla; the type of occlusion of the individual; presence or absence of decay in central, and whether the patient has normal frenum or abnormal frenum.

To determine normal or abnormal frenum, the blanching test and the pull-syndrome, (i.e., paying attention to the displacement of free gingival during the pulling of the lip) was used. So that after the pulling of the upper lip with a tongue depressor, gentle pressure is put on frenum.

If the soft tissue of the lingual side and the gingiva between the central teeth and the interdental papilla were white and if free gingiva swirled, frenum was considered abnormal. Of these children, those with systemic diseases, congenital anomalies, and decay in maxillary central teeth or any changes in the size and shape of maxillary central teeth, were excluded from our study. Limitations and difficulties during the work: (a) long official procedures for obtaining a permit from the welfare organization of Tehran province, (b) distribution of kindergartens in the city of Tehran, (c) lack of cooperating the authorities of some kindergartens, (d) lack of cooperating of some children.
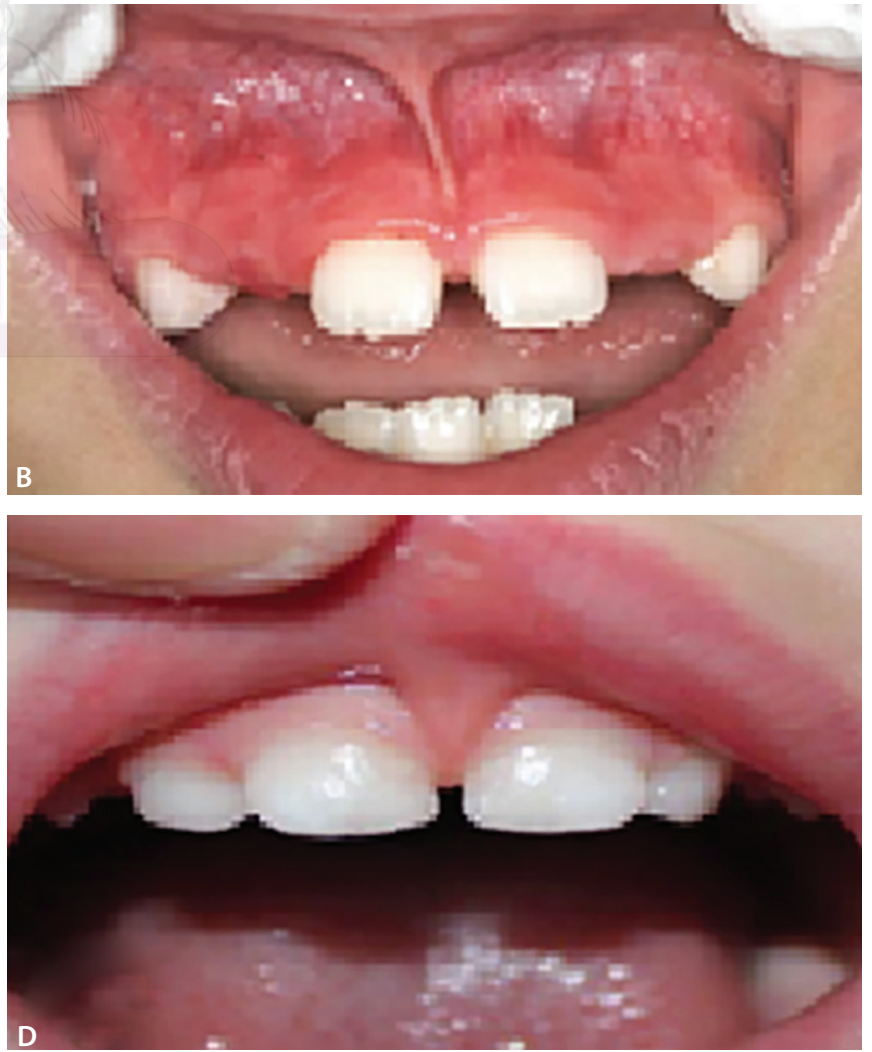

Figs 2A to D: Types of frenum. (A) Mucosal frenum; (B) Gingival frenum; (C) Papillary frenum; (D) Papillary penetrating frenum 
After explaining the research plan for kindergarten authorities and convincing them about the usefulness of this research result in promoting oral and dental health in the community, we were able to complete our work at these centers. To attract the children's cooperation, we also talked to them with a simple and childish language about mouth and tooth and educate them about oral and dental health, so that we attract their trust, and we did this research.

Data were analyzed by descriptive and analytic statistics using statistical package for social sciences (SPSS) version 23 software at a significant level of 0.05 . In the analytic part to test the research hypotheses according to the type of mean and the desired variables, binomial logistic regression test was used. In the descriptive part, tables and charts were adjusted and described.

The present study was submitted to the research committee of the Tehran University of Medical Sciences prior to the registration and the code of ethics 97/D/130/1785 was received.

\section{Results}

Totally, 639 children aged 3-6years were studied, which 341 (53.3\%) were male and 298 (46.7\%) were female.

The rate of gingival frenum was 338 people (52.9\%) and mucosal frenum was 127 people (19.9\%) and papillary was 120 people (18.8\%) and papillary penetrating was 54 (8.5\%). The highest prevalence of frenum was related to the gingival type and the least prevalence was papilla penetrating (Graph 1).

There is no statistically significant difference between the sexes in the prevalence of different types of labia frenum ( $p$ value $=$ 0.496) (Table 1).

Among the 639 children examined, 214 (33.5\%) had high frenum and 425 (66.5\%) had normal frenum, and the results showed that between high frenum and median diastema had a statistically significant relationship ( $p$ value $=0.014)($ Graph 2).

Among the 639 children examined, 214 (33.5\%) had high frenum and $425(66.5 \%)$ had normal frenum, and the results showed that

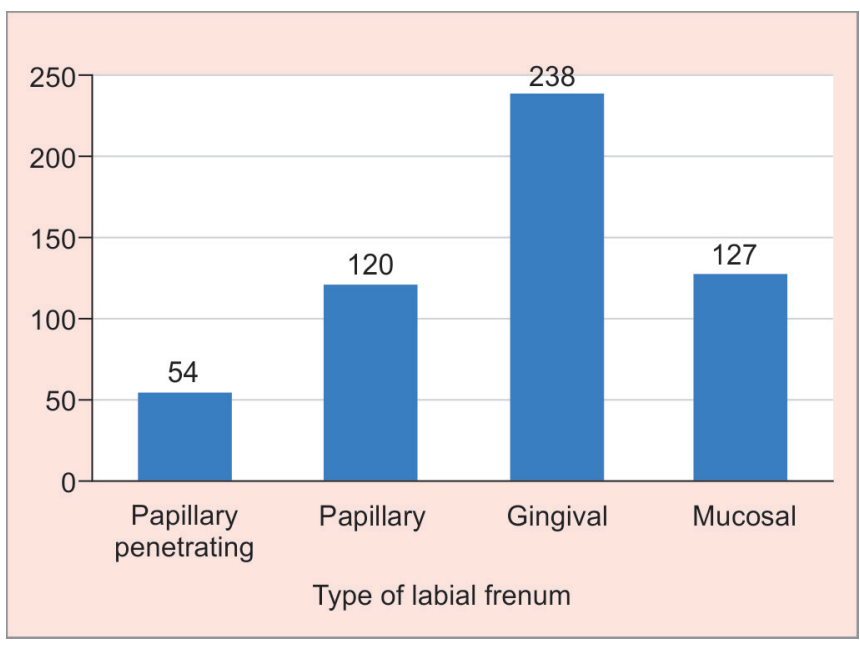

Graph 1: Prevalence of labial frenum

between high frenum and median diastema had a statistically significant relationship ( $p$ value $=0.014)($ Graph 2$)$.

According to Table 2:

- Among 127 people who had mucosal frenum, no one had high frenum.

- Among 338 people who had gingival frenum, 65 people $(19.2 \%)$ had abnormal frenum.

- Among 120 patients with papillary frenum, 95 people (79.2\%), had abnormal frenum.

- Among 54 people who had papillary penetrating frenum, all of them (i.e. ,100 percent) had an abnormal frenum.

No significant relationship was found between age and high frenum in this study (Table 3). According to the findings of the study, the following results were obtained from the prevalence

Table 1: Distribution of prevalence of different types of maxillary labial frenum in different genders

\begin{tabular}{llllll}
\hline Type of frenum & Mucosal & Gingival & Papillary & Papillary penetrating & Total \\
\hline Boy & 73 & 183 & 59 & 26 & 341 \\
& $(21.4 \%)$ & $(53.7 \%)$ & $(17.3 \%)$ & $(7.6 \%)$ & $(100 \%)$ \\
Girl & 54 & 155 & 61 & 28 & 298 \\
& $(18.1 \%)$ & $(52 \%)$ & $(20.5 \%)$ & $(9.4 \%)$ & $(100 \%)$ \\
\hline Total & 127 & 338 & 120 & 54 & 639 \\
\hline
\end{tabular}

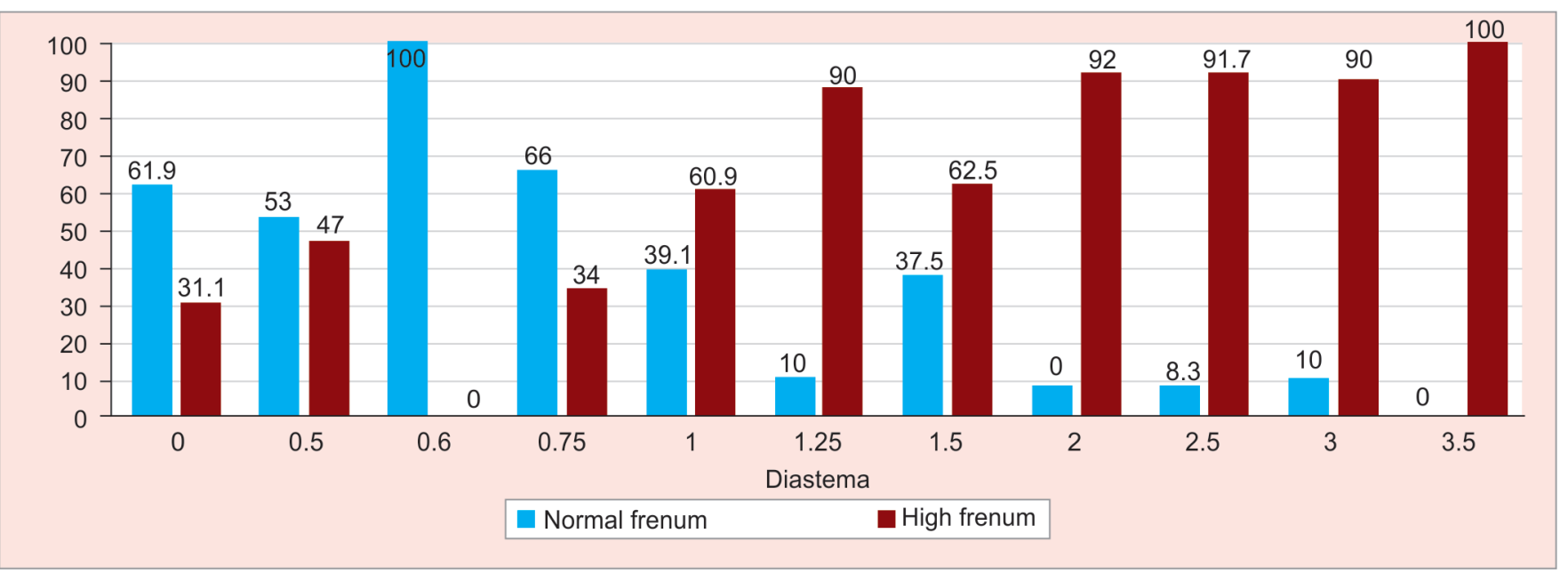

Graph 2: Relationship between high frenum and maxillary median diastema 
Maxillary Labial Frenulum and Median Diastema

Table 2: Prevalence of high frenum in different types of maxillary labial frenum

\begin{tabular}{|c|c|c|c|c|}
\hline Type of frenum & Mucosal & Gingival & Papillary & Papillary penetrating \\
\hline $\begin{array}{l}\text { High } \\
\text { frenum }\end{array}$ & $\begin{array}{l}0 \\
(0 \%)\end{array}$ & $\begin{array}{l}65 \\
(19.2 \%)\end{array}$ & $\begin{array}{l}95 \\
(79.2 \%)\end{array}$ & $\begin{array}{l}54 \\
(100 \%)\end{array}$ \\
\hline Normal frenum & $\begin{array}{l}127 \\
(10.9 \%)\end{array}$ & $\begin{array}{l}273 \\
(80.8 \%) \\
\end{array}$ & $\begin{array}{l}25 \\
(20.8 \%) \\
\end{array}$ & $\begin{array}{l}0 \\
(0 \%)\end{array}$ \\
\hline Total & $\begin{array}{l}127 \\
(100 \%)\end{array}$ & $\begin{array}{l}338 \\
(100 \%)\end{array}$ & $\begin{array}{l}120 \\
(100 \%)\end{array}$ & $\begin{array}{l}54 \\
(100 \%)\end{array}$ \\
\hline
\end{tabular}

Table 3: Relationship between age and high frenum and normal frenum

\begin{tabular}{|c|c|c|c|c|c|}
\hline Age & 3 & 4 & 5 & 6 & Total \\
\hline Normal frenum & $\begin{array}{l}140 \\
(69.3 \%)\end{array}$ & $\begin{array}{l}107 \\
(69 \%)\end{array}$ & $\begin{array}{l}97 \\
(60.6 \%)\end{array}$ & $\begin{array}{l}81 \\
(66.4 \%)\end{array}$ & $\begin{array}{l}425 \\
(66.5 \%)\end{array}$ \\
\hline High frenum & $\begin{array}{l}62 \\
(30.6 \%)\end{array}$ & $\begin{array}{l}48 \\
(30.9 \%)\end{array}$ & $\begin{array}{l}63 \\
(39.3 \%)\end{array}$ & $\begin{array}{l}41 \\
(33.6 \%)\end{array}$ & $\begin{array}{l}214 \\
(33.5 \%)\end{array}$ \\
\hline Total & $\begin{array}{l}202 \\
(100 \%)\end{array}$ & $\begin{array}{l}155 \\
(100 \%)\end{array}$ & $\begin{array}{l}160 \\
(100 \%)\end{array}$ & $\begin{array}{l}122 \\
(100 \%)\end{array}$ & $\begin{array}{l}639 \\
(100 \%)\end{array}$ \\
\hline
\end{tabular}

of occlusion in children aged 3-6 years. These results are merely descriptive and have not been the subject of this research.

- Occlusion mesial step $=358$ people $(56.11 \%)$

- Occlusion distal step $=30$ people $(40.7 \%)$

- Occlusion flush terminal = 191 people (29.9\%)

- Occlusion class $1=42$ people $(6.5 \%)$

- Occlusion class $3=14$ people $(2.19 \%)$

- Occlusion class $2=4$ people $(0.4 \%)$

From the total number of subjects in the study, 98 anterior spacing were observed. In 541 people no anterior spacing was observed. There was a statistically significant relationship between anterior spacing and high frenum ( $p$ value $=0.02$ ).

\section{Discussion}

Some of disadvantages and disturbances that frenum abnormality causes are diastema, abnormal position of the anterior central incisors, rapid dental caries, periodontal problems during food remaining and impaction, esthetic problems and upper lip damage. In case of problems and complaints from the patient, treatment should be initiated, which can be a frenectomy using a surgical blade or a laser, which in some studies are stated that laser treatment is useful, simple and safe, and in the absence of a problem or complaint, the patient will be followed regularly until the age of 10 and should wait until this age. ${ }^{15}$

The aim of this study was to determine the prevalence of different types of labial frenum and their effects on median diastema in children aged 3-6 years in Tehran kindergartens. In this study, a total of 639 children in the age group of 3-6 years were studied. The rate of gingival frenum was 338 (52.9\%), and mucosal frenum was 127 (19.9\%), and papillary was 120 (18.8\%), and papillary penetrating was 54 (8.5\%) (Graph 1).

The highest prevalence of frenum was related to gingival, and the lowest prevalence was related to papilla penetrating.

Maria's study, in 2017 which evaluated the labial frenum in newborn infants, found that the highest prevalence of frenum was related to gingival frenum (83\%). The results of this study were the same as our results. ${ }^{16}$

In the study of Laohapensang et al. in 2017 with a mean age of 8.7 years old children, the highest prevalence of gingival frenum was $70 \%$, mucosal was $18.8 \%$, and papillary was $7.3 \%$, and the lowest incidence was $4 \%$ and related to papillary penetrating frenum.
The result of this study was the same as our results, and similar to the current study, the highest prevalence was gingival frenum and the least was papillary penetrating. ${ }^{17}$

Adhesion and a sufficient connection of the frenum to the gingiva is essential for gingiva health, and also the gingiva frenum restricts the movements of the structures, especially the anterior maxilla, so it is natural that the prevalence of gingival frenum, which is a physiologic state, be higher, on the other hand, the long or flat frenum without adhesion to permanent teeth gingiva or when frenum extends between the interdental papilla, these are pathologic condition. ${ }^{18}$

On the contrary, a study was done by Rajani in India, in which, unlike our study, the mucosal type was the most common and papillary penetrating was the least prevalence. This difference is related to the higher age group studied in their study, which is the age group of 13-30-year-old they have reviewed. ${ }^{18}$

In our study, both males and females had the highest prevalence of gingival frenum (boys $=53.7 \%$ ), (girls $=52 \%$ ). The papillary penetrating type was lowest in both sexes (boys = $7.6 \%$, girls $=9.4 \%$ ), and also in our study there was no significant difference in sex with the prevalence of different types of frenum ( $p$ value $=0.496$ )

The results of the study of Laohapensang and Díaz-Pizán, similar to our present study, did not show any significant difference in sex with the prevalence of frenum. ${ }^{18,19}$ Among the 639 children examined, 214 (33.5\%) had high frenum and 425 (66.5\%) had normal frenum, and the results showed that there was a significant relationship between high frenum and median diastema ( $p$ value $=$ 0.014).

The results of Rajani's study contradict current study and there is no statistically significant relationship between high frenum and median diastema. ${ }^{18}$

The results of Sękowska's study similar to our study also showed that there was a statistically significant relationship between high frenum and median diastema ( $p$ value $<0.05) .{ }^{20}$

Sagar et al. in 2017 examined the prevalence of all labial frenum types, ${ }^{20}$ and contrary to the results of our study, they found that there was no significant relationship between the type of frenum and diastema. This contradiction in the results may be due to the difference in the classification of the frenum groups. They divided frenum according to morphology into groups of persistent tectolabial frenum, simple frenum with 
appendix, simple frenum with nodule, double frenum, Frenum with nichum, bifid frenum, frenum with two or more variations, but we categorized groups based on their location and normality, so that we found a significant correlation between the normal frenum and the diastema size.

Boutsi et al. in 2011 designed a study on children aged 5.5 -11.5 years which found that there was a significant relationship between age and type of frenum. ${ }^{21}$ The result of their study is compatible with our study.

\section{Conclusion}

Generally, in this research, 639 children of 3-6 years old were examined and studied and the following results obtained: The rate of labial frenum of maxilla prevalence is such as follows: the most common frenum is respectively related to gingival and then papillary, and papilla penetrating.

The prevalence and types of maxilla labial frenum due to sexual division and $p$ value of 0.496 showed that there was no statistically significant difference between two sexes in prevalence of different types of maxilla labial frenum.

Among all of the children examined, 214 people (33.5\%) had abnormal frenum (high frenum) and 425 people (66.5\%) had normal frenum.

According to $p$ value $=0.014$, it is concluded that there is a correlation between the high frenum and the maxilla median diastema in this study.

In terms of the prevalence of occlusion, the highest prevalence was related to mesial step and the lowest prevalence was related to occlusion class II.

\section{SUGGESTIONS}

It is suggested that a longitudinal study be carried out in following of this research, so that with the information obtained from these individuals and following up the patients with abnormal frenum in the age group of 3-6years, the status of frenum and periodontium of these individuals at later ages and in mixed dentition period, as well as the period of permanent dentition, be examined to provide useful information on the treatment or non-treatment of abnormal frenum at an earlier age.

\section{Clinical significance}

Diastema is one of the many esthetic abnormalities due to various causes. One of which is abnormal frenulum. Also, diastema causes discomfort to the patients and parents.

\section{References}

1. Mayers RE. Handbook of orthodontics for the student and general practitioner. 3rd ed. Chicago: Ann Arbor; 1934.

2. Cohen MM. Minor tooth movement in growing child. 3rd ed. Philadelphia: Sunders company; 1977.

3. Oesterle LJ, Shellhart WC. Maxillary midline diastemas: a look at the causes. J Am Dent Assoc 1999;130(1):85-94

4. Koora K, Muthu MS, Rathna PV. Spontaneous closure of midline diastema following frenectomy. J Indian Soc Pedod Prev Dent 2007; 25(1):23-26.

5. Sanin C, Sekiguchi T, Savara BS. A clinical method for the prediction of closure of the central diastema. ASDC J Dent Child 1969;36(6):415 418.

6. Graber TM. Orthodontic principles and practice. $3 r d$ ed. Philadelphia: WB Saunders Co; 1972.

7. Hirschfeld L, Geiger A. Minor tooth movement in general practice. 3rd ed. St. Louis: Mosby; 1974.

8. Popovich F, Thompson GW. Maxillary diastema: indications for treatment. Am J Orthod 1979;75(4):399-404.

9. Houston WJB. A textbook of orthodontics. 2nd ed. Oxford London: Wright; 1994.

10. Hitchcock HP. Orthodontics for undergraduate. 6th ed. Philadelphia: Lea and Febiger; 1974.

11. Moullas AT. Maxillary midline diastema: a contemporary review. Hell Orthod Rev 2005;8(2):93-103.

12. Andrews LF. The six keys to normal occlusion. Am J Orthod 1972; 62(3):296-309.

13. Broadbent BH. Ontogenic development of occlusion. Angle Orthod 1941;11(4):223-241.

14. Lakhani N, Vandana KL. Diastema and Frenum-An Insight. Saudi J Oral Dent Res 2016;1(3):96-101

15. Komori S, Matsumoto K, Matsuo K, et al. Clinical Study of Laser Treatment for Frenectomyof Pediatric Patients. Int J Clin Pediatr Dent 2017;10(3):272-277.

16. Santa Maria C, Aby J, et al. The superior labial frenulum in newborns: What is normal? Glob Pediatr Health 2017;4:2333794X17718896.

17. Laohapensang $M$, Nakarerngrit $C$, Petsongkram B, et al. The Association between the Midline Diastemas and the Superior labial frenum. J Med Assoc Thai 2017;100(3):90.

18. Rajani ER, Biswas PP, Emmatty R. Prevalence of variations in morphology and attachment of maxillary labial frenum in various skeletal patterns-A cross-sectional study. J Indian Soc Periodontol 2018;22(3):257.

19. Sękowska A, Chałas R. Diastema size and type of upper lip midline frenulum attachment. Folia Morphol 2017;76(3):501-505.

20. Sagar S, Heraldsherlin J, Moses S. Morphological variation of abnormal maxillary labial frenum in South Indian population. Int J Pharm Sci Res 2016;7:2142-2146.

21. Boutsi EA, Tatakis DN. Maxillary labial frenum attachment in children. Int J Pediatr Dent 2011;21(4):284-288. 